\title{
NOS RITMOS DAS LAPAS - PASSOS DE UMA ETNOGRAFIA DE RUA
}

Diego Pontes ${ }^{1}$

\section{Introdução}

\section{Breves olhares sobre o cotidiano da Lapa carioca - notas de um espaço em movimento}

Considerando as diversas transformações urbanísticas que envolvem a estrutura da Lapa $^{2}$, tradicional bairro localizado na região central da cidade do Rio de Janeiro, a proposta aqui apresentada é percorrer algumas pistas que nos auxilie a compreensão das transformações socioespaciais pelas quais passou essa região, assim como refletir acerca de seu cotidiano, abrindo caminho para que seja também analisado o processo de consolidação de significados que, ainda hoje, associam essa região a determinados ethos e visões que compõem o imaginário sobre a vida urbana na Lapa.

Quando trazemos para reflexão o bairro da Lapa, podemos inicialmente considerar que trata-se, na atualidade, de uma área conhecida pelo seu intenso movimento e alto fluxo turístico que compreende uma enorme variedade de bares, casas noturnas, pubs, barracas e ambulantes que configuram um lugar de múltiplos usos e ambivalentes significados. A respeito de seu cotidiano, "entre as ruas, becos e esquinas" que compõem a Lapa (Caruso, 2016), misturam-se habitações residenciais, pessoas em situação de rua, cortiços, condomínios, casarões em ruínas, hostels, pousadas e imponentes hotéis que se encontram em um circuito fortemente envolvido pelo consumo urbano e uma lógica turística voltada à projeção nacional e internacional do bairro.

Uma gama de estudos urbanos que apreendem a Lapa como campo de investigação destaca uma atmosfera composta pela multiplicidade, sobreposições e diversos fluxos e sentidos atribuídos a essa região da cidade. Investigações no campo da Geografia Cultural, História, Comunicação, Antropologia, Planejamento Urbano, Arquitetura e Urbanismo percorrem justamente as transformações ocorridas tanto em

\footnotetext{
${ }^{1}$ Universidade Federal de Santa Catarina, Brasil. $\quad$ E-mail: diegopontez@gmail.com. ORCID: https://orcid.org/0000-0002-4374-1269.

2 Para este artigo considero especificamente as transformações impulsionadas e desencadeadas pelos megaeventos - Copa do Mundo, em 2014, e as Olimpíadas em 2016 (Maior, 2014; Viana, 2019) -, com a implementação do Veículo Leve sobre Trilhos (VLT), que percorre as proximidades da Lapa pela Cinelândia, e ainda a intensificação do dispositivo de patrulhamento de segurança pública Lapa Presente.
} 
sua estrutura física ao longo do tempo, quanto no que diz respeito às dinâmicas urbanas do cotidiano por suas distintas temporalidades e espacialidades (Silva, 1993; Casco, 2007; Herschmann, 2007; Bartoly, 2011; Guterman, 2012; Fazzioni, 2014; Souza, 2015; Caruso, 2016).

Em termos históricos, as transformações urbanas ocorridas no cotidiano da Lapa carioca remontam emaranhados processos que envolvem uma série de negociações, conflitos e fronteiras muitas vezes pouco nítidas entre empreendimentos públicos e privados. No que diz respeito a algumas dessas mudanças e reinvenções sobre essa região, destaca-se o período que compreende seu apogeu, durante as décadas de 19201940, em que a região representava uma importante centralidade econômica e cultural da cidade do Rio de Janeiro, e, com o passar dos anos, seu processo de decadência e degradação, onde a região tornou-se obsoleta aos investimentos públicos ao passo que a cidade se expandia rumo a outras zonas urbanas (Bartoly, 2011).

Outro ponto importante ressaltado por autores e autoras que retratam as transformações urbanas pela Lapa refere-se ao período de sua "redescoberta", que tem como marco o início dos anos 2000, onde essa região, com seus 49.909 habitantes distribuídos por $2093,859 \mathrm{~km}^{2}$ de extensão ${ }^{3}$, passou a ser reconfigurada por políticas urbanísticas e de segurança voltadas ao alavancar das forças do turismo e da especulação imobiliária, impulsionando uma série de revitalizações, requalificações e reconfigurações da vida urbana a partir desse período (Martins e Oliveira, 2008; Souza, 2015).

Abre-se, com isso, caminho para investigação de algumas nuances referentes às transformações que marcaram e tiveram impacto direto nas articulações relacionadas ao mercado do turismo, que acabam, por sua vez, incidindo diretamente sobre a vida ordinária do espaço vivido da Lapa. Essa dinâmica envolve, além das questões específicas relativas à segurança pública a partir da implementação de programas voltados a construção de uma ideia de ordenação do espaço urbano, conforme sinaliza Haydeé Caruso (2014), mas também uma série de restaurações estratégicas. Dentre essas transformações, podemos citar como exemplo as ocorridas nos Arcos da Lapa e seus bondes, no centro cultural Sala Cecília Meireles, no 'Grande Hotel Bragança' e no Circo Voador, assim como as mudanças urbanísticas na mais movimentada Avenida da Lapa, a Mem de Sá, com a requalificação de casarões antigos que se distribuem por sua

\footnotetext{
${ }^{3}$ Segundo consta no censo demográfico do IBGE de 2019.
} 
extensão e que, hoje, abrigam hostels, depósitos de bebidas, lan house, motéis baratos, tabacaria, bancas de jornal, funerárias, restaurantes e bares.

Trata-se, na atualidade, de um lugar que abriga paradoxos, (des)encontros e colisões distintas que se expressam em contradições, fronteiras e tensões sobre o cotidiano dessa região, materializadas, inclusive, em uma gama de sociabilidades e encontros que corporificam o bairro, como podemos observar em suas feiras de antiguidades e artesanatos, brechós, festas e bares LGBTQIA+, rodas de samba, jogos de futebol na televisão dos bares, redes de distribuição de refeições para pessoas em situação de rua, manifestações políticas e festas de carnaval.

Dito isso, o objetivo do trabalho aqui apresentado consiste em compreender as transformações urbanas e as interferências no espaço cotidiano habitado da Lapa nos dias de hoje, pensando a dinâmica dos entrelaçamentos entre os usuários da cidade em suas experiências urbanas e distintas formas de ocupação, para então refletir sobre os modos que esse espaço se constrói no Rio de Janeiro em termos de representação da cultura urbana carioca. Proponho, dessa forma, uma reflexão a partir de fragmentos da Lapa vivida e sentida em seus diversos ritmos, colisões e profusões de transformações e significados, dando, para tanto, atenção específica ao espaço praticado (Certeau, 2014) como meio de análise do cotidiano urbano dessa região.

As questões que se levantam neste trabalho caminham de encontro ao debate sobre o espaço urbano enquanto extensão corpórea e lugar de atravessamentos e conflitos, tal como sugere Paola Jacques (2010) e Manuel Delgado (2007, 2011) ao considerem um olhar que envolve as zonas espaciais em tensão impulsionadas por um contexto urbano imerso em políticas de transformações, dispositivos de controle e resistências que configuram a vida citadina contemporânea.

No que diz respeito ao olhar debruçado sobre o cotidiano, Cornelia Eckert e Ana Luiza Carvalho da Rocha (2013) trazem uma importante perspectiva que nos permite pensar as dinâmicas urbanas como espaços de confluência que se constroem nas interações e encontros dos diversos agentes sociais que circulam e fazem a vida urbana. Ademais, reside ainda nessa ótica a compreensão do cotidiano como lugar do inesperado e do 'desendereço', onde podemos destacar a potencialidade dessa forma de apreensão da realidade urbana de modo transversal e aberta a transformações, nos fazendo questionar, portanto, acerca dos desafios do exercício etnográfico em realidades urbanas tão distintas, distantes, familiares e, como também condiz ao cotidiano, fugazes. 
Com isso, as reflexões aqui brevemente apresentadas se desenham por meio da etnografia de rua, onde esse movimento pela cidade se faz fundamentalmente no entendimento do caminhar enquanto leitura e escrita das formas de 'experienciação' das e nas cidades, nos levando, aqui neste artigo, ao olhar para a coexistência de diversas Lapas em suas múltiplas ambiências, ritmos, frequências e contradições.

Figura 1 - Cruzando os Arcos, marcas no muro da Avenida Mem de Sá.

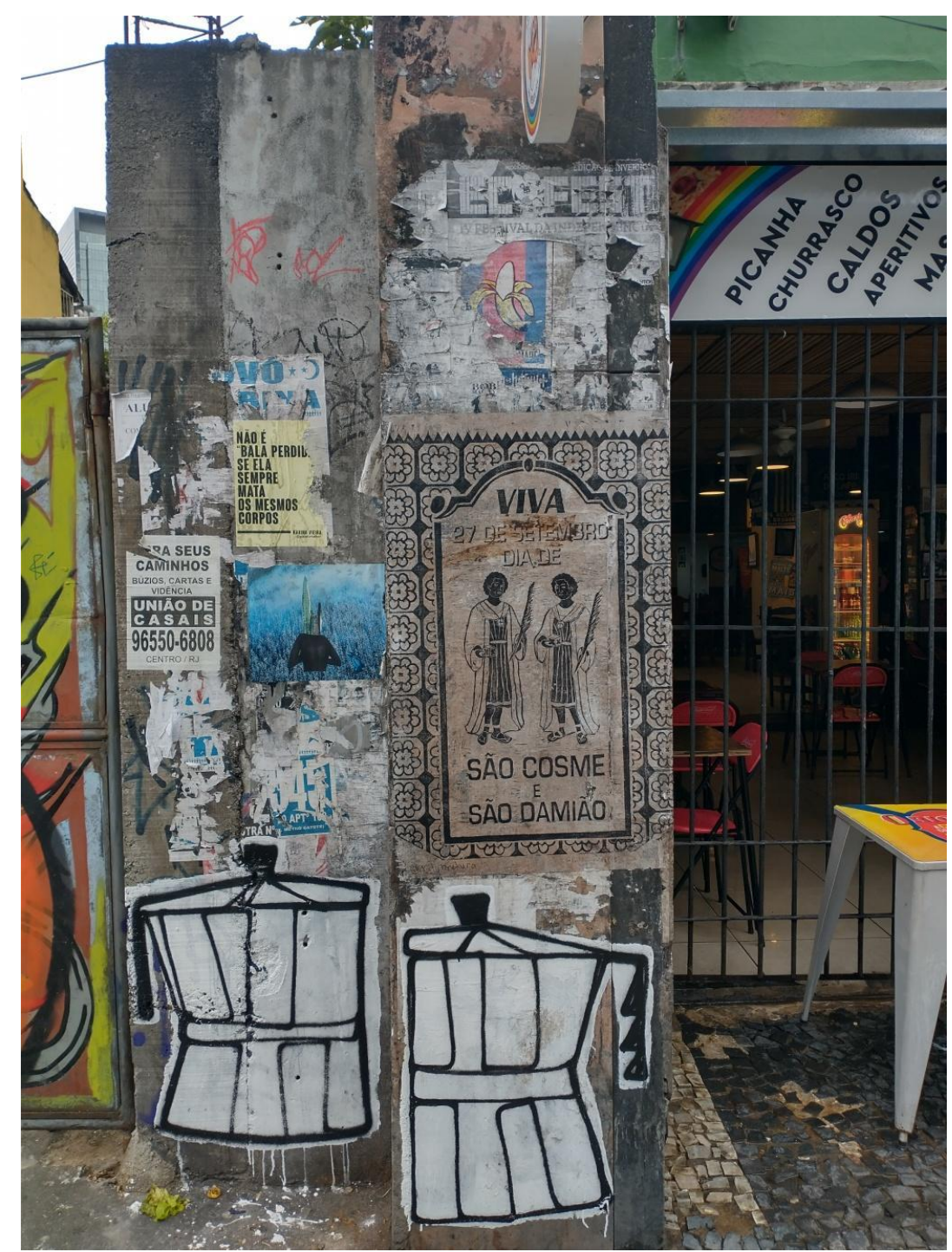

Fonte: Acervo pessoal, 2020

\section{Alguns apontamentos sobre as transformações pela Lapa}

A escolha inicial pela investigação e delimitação espacial da Avenida Mem de Sá e adjacências - considerada pelas projeções do turismo a principal e mais 
movimentada via da Lapa - como meio que substancialmente cruza e orienta o universo da pesquisa, se coloca como caminho por onde proponho o desenvolvimento desta investigação, que, aliás, remonta minhas próprias vivências, memórias e saídas de campo sobre essa região da cidade que é, para mim, com muitas ressalvas, familiar.

A respeito das possibilidades analíticas sobre a Lapa, considero a perspectiva de Gilberto Velho quanto à observação do familiar, na qual se faz, com toda sua complexidade e relativizações, a partir do olhar para a própria sociedade do pesquisador por meio de uma ótica "preocupada em perceber a mudança social não apenas ao nível das grandes transformações históricas, mas como resultado acumulado e progressivo de decisões e interações cotidianas" (Velho, 2013: 79).

O ponto de partida para esta análise entende que a Lapa abriga uma série de elementos históricos e representações específicas na cultura urbana da cidade, seja pelo imaginário da boemia, malandragem, diversidade, ou ainda pela imponência ou abandono de seus patrimônios, como a Sala Cecília Meireles, a Escola de Música da UFRJ, a Escadaria Selarón, além dos próprios Arcos da Lapa. Com isso, venho buscando observar a maneira que esse cotidiano é construído na dinâmica da cidade nos dias de hoje, destacando quais redes de sociabilidades abriga, assim como quais processos de patrimonialização e tombamento alicerçam suas representações.

No que abarca essa região, uma considerável promoção por meio de empreendimentos sobre o espaço urbano desembocou, desde o final doa anos de 1990, em uma espécie de 'redescoberta' da Lapa aos moldes do mercado nas últimas décadas (Caruso, 2016). Nesse panorama caleidoscópico de transformações, podemos considerar tanto mudanças ligadas à própria estrutura física da Lapa, como também as relacionadas à ordem e segurança pública dessa região, indelevelmente impactadas pelas políticas voltadas ao turismo e a especulação imobiliária.

Segundo Haydeé Caruso, transformações recentes que incidem a retomada do bairro da Lapa por investimentos orientados pela lógica do mercado e do espaço urbano capitalista, que visionam a exploração da identidade do lugar em termos mercadológicos, criando estereótipos e promovendo a reconfiguração e valorização de uma região historicamente marcada por profundas modificações em sua estrutura. Dessa dinâmica, torna-se possível observar um processo de reinvenções e reafirmações de narrativas sobre o período de seu apogeu, de sua decadência e, na atualidade, de sua atmosfera hype a partir dos anos 2000, onde foi fortemente impactada pelas demandas do turismo e por diversos outros processos de revitalizações, requalificações e 
gentrificação em outros perímetros da região central do Rio de Janeiro (Martins e Oliveira, 2008; Caruso, 2016).

Essas reconfigurações podem ser pensadas dentro de um quadro de análise que situa uma dinâmica de retomadas e 'reinvenções' de áreas centrais das grandes cidades ao redor do mundo, e em particular nas metrópoles brasileiras impulsionadas a partir da década de 1990, onde segundo Martins e Oliveira (2008),

\begin{abstract}
Projetos de (re)valorização urbana implementados nas áreas centrais de diferentes cidades mundiais têm em comum o estímulo à construção de grandes equipamentos culturais, a promoção de atividades turísticas, revalorização do patrimônio histórico-cultural e do espaço público. O estudo dos processos de transformações urbanas promovidas por esses projetos tem grande relevância à medida que possibilitam entender como alteram o conteúdo social, cultural e físico dos espaços afetados. Desvendar as nuanças dos recentes processos de apropriação do patrimônio históricocultural é de grande importância para entender as políticas contemporâneas de "revitalização" que reinventam lugares, recriam tradições, estabelecem centralidades: aspectos a partir dos quais outros lugares são criados e outras tradições reapropriadas, a partir dos usos diferenciados que se faz dos espaços públicos. (Martins e Oliveira, 2008: 159).
\end{abstract}

Os autores, ao questionarem $O$ que está acontecendo coma Lapa?, pontuam um conjunto de processos, a um primeiro olhar não necessariamente associados, mas que anunciam um espaço a ser criado e ocupado envolvido sob a métrica das forças do mercado, tendo sua estrutura física sofrido significativas alterações incidindo em mudanças nas dinâmicas cotidianas dessa região. Trata-se, segundo Martins e Oliveira, da compreensão de um espaço constituído por processos de revitalização, renovação, requalificação, reabilitação urbana ou mesmo de gentrificação em zonas antes consideradas degradadas e que indicam fluxos de reinvenções sobre a vida urbana e, consequentemente, das formas de experimentação e ocupação da cidade.

Dito isso, dentro do quadro de análise dos impactos das revitalizações nas dinâmicas urbanas, este trabalho busca lançar luz sobre alguns fragmentos do cotidiano da Lapa em diálogo também com estudos que apontam para um cenário reconfigurado pelos últimos megaeventos ocorridos na cidade do Rio de Janeiro - a Copa do Mundo, em 2014, e as Olimpíadas em 2016 (Maior, 2014; Viana, 2019). Megaeventos que, segundo Viana (2019), impactaram de forma arbitrária as cidades como um todo, e, no caso do Rio de Janeiro, pontualmente em áreas consideradas estratégicas aos olhos do turismo, do mercado imobiliário e da segurança pública, como Copacabana, região 
Portuária, Maracanã e Lapa, além da criação e desenvolvimento de novos espaços turísticos e projetos de mobilidade e segurança, como o Porto Maravilha, as novas linhas de escoamento do trânsito e a ampliação do patrulhamento por meio de uma intensificação do Programa Segurança Presente articulado pelo poder público.

No que diz respeito a essa específica região, as atuais transformações podem ser observadas a partir da construção e implementação, em 2016, no bojo das Olimpíadas, do Veículo Leve sobre Trilhos (VLT), que percorre as proximidades da Lapa pela estação da Cinelândia, e também a intensificação do dispositivo de patrulhamento de segurança pública Lapa Presente, implementado desde 2015 pelo governo do Estado e prefeitura do Rio de Janeiro, e que hoje existe em diferentes bairros e localidades 'estratégicas' da cidade (Maior, 2014; Viana, 2019).

Assim, considerando para esta inflexão o cotidiano atual da Lapa em suas multiplicidades, coexistências e transformações, características fundamentais da experiência urbana contemporânea, destaco passos que possam auxiliar a ampliação da compreensão do panorama urbano do bairro e a relação dos usuários e dos significados atribuídos a esse espaço, que se traduzem em modos diversos de ocupá-lo.

Figura 2 - Cruzamento da Mem de Sá com a Rua dos Inválidos.

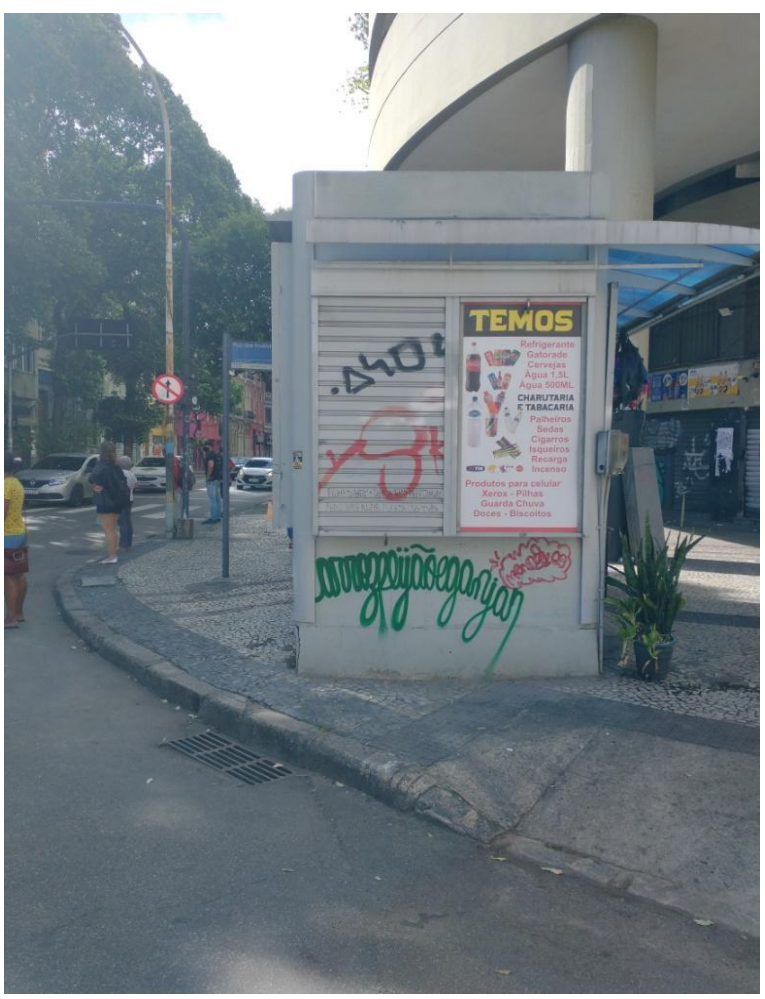

Fonte: Acervo pessoal, 2020. 
Figura 3 - Cruzamento da Av. Mem de Sá com a Gomes Freire em uma manhã de sábado, após uma movimentada sexta feira.

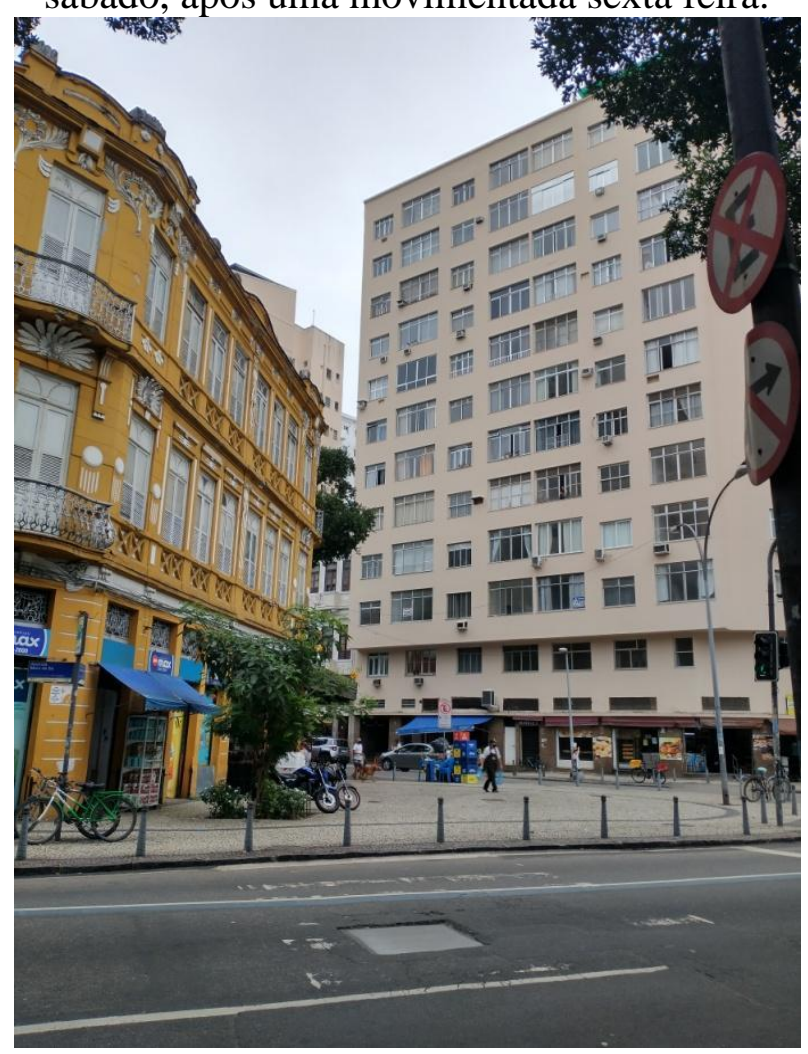

Fonte: Acervo pessoal, 2020.

Figura 4 - Cardápio na calçada dos restaurantes e bares pela Av. Mem de Sá. 


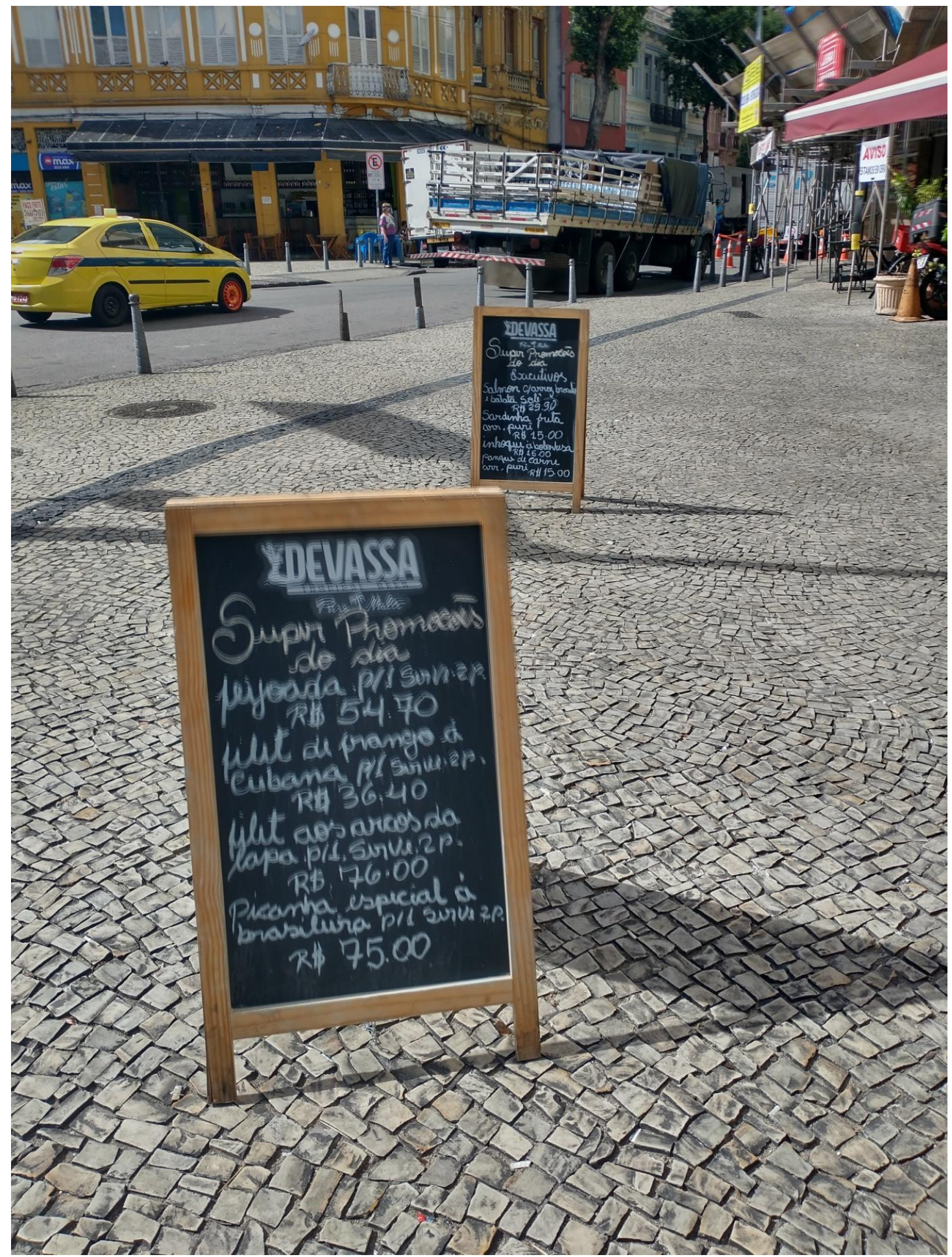

Fonte: Acervo pessoal, 2020

\section{Cruzando os Arcos das Lapas}

Caminhar pela Lapa, cruzar suas ruas, arcos e esquinas que abrigam movimentos distintos (Casco, 2007), nos permite evidenciar uma gama de ritmos ambivalentes que podem ser observados pela diversidade de formas de habitação, 
sotaques, idiomas, músicas, festas, grafites e pichações que bordam sua atmosfera, e que neste artigo marcam a compreensão sobre o espaço praticado dessa região como um emaranhado de contradições, sobreposições e coexistências, sendo assim possível notar um verdadeiro caleidoscópio de Lapas que coexistem.

Uma composição atravessada por usos que se transformam no decurso das horas e dias da semana, como revela Natália Fazzioni (2014) em sua etnografia sobre a Lapa em seus tempos múltiplos e sobrepostos, onde analisou o processo de transformações das dinâmicas urbanas dessa região, desencadeado, segundo a autora, desde os anos 2000 quando um conjunto de políticas públicas voltadas ao bairro se desdobrou em mudanças na estrutura urbana por meio de reformas de vias, revitalizações, tombamentos e processos de preservação do patrimônio edificado e seus usos.

Pensando a cidade enquanto objeto temporal, Fazzioni aborda as dinâmicas do turismo entendendo os Arcos da Lapa como uma espécie de portal marcador liminar entre o "antes e depois dos arcos", onde se torna possível percorrer nitidamente uma rua e seus dois lados. Corpos e formas de habitar que se expressam em contrastes e paradoxos entre seus polos: "um mais empobrecido e outro mais elitizado, tanto do ponto de vista dos frequentadores, quanto dos moradores, o que pode ser igualmente constatado pelo tipo das edificações existentes em cada um dos lados" (Fazzioni, 2014: 294).

Figura 5 - Cruzamento da Mem de Sá com a Rua do Lavradio. 


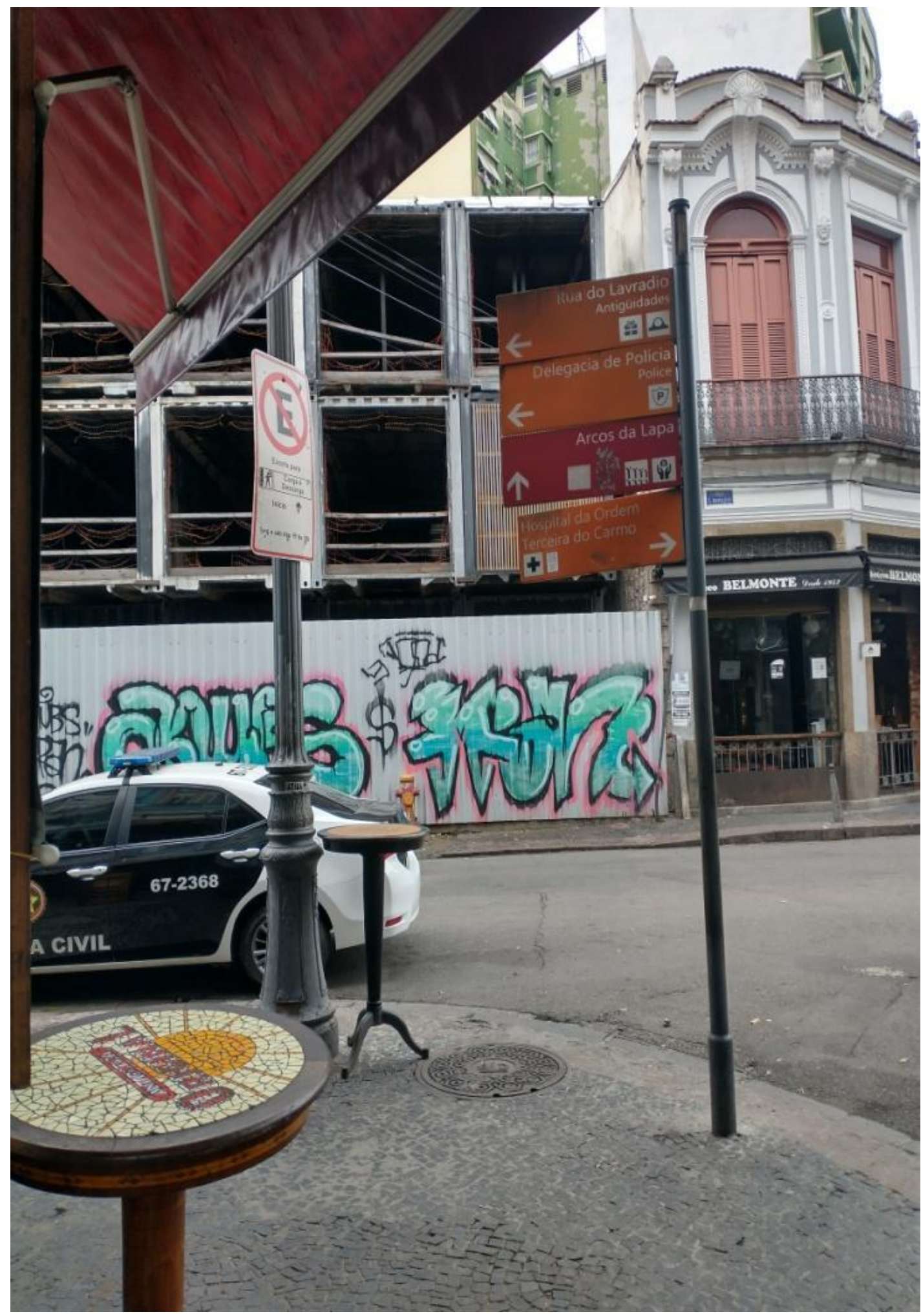

Fonte: Acervo pessoal, 2020.

Figura 6 - Rua dos Inválidos. 


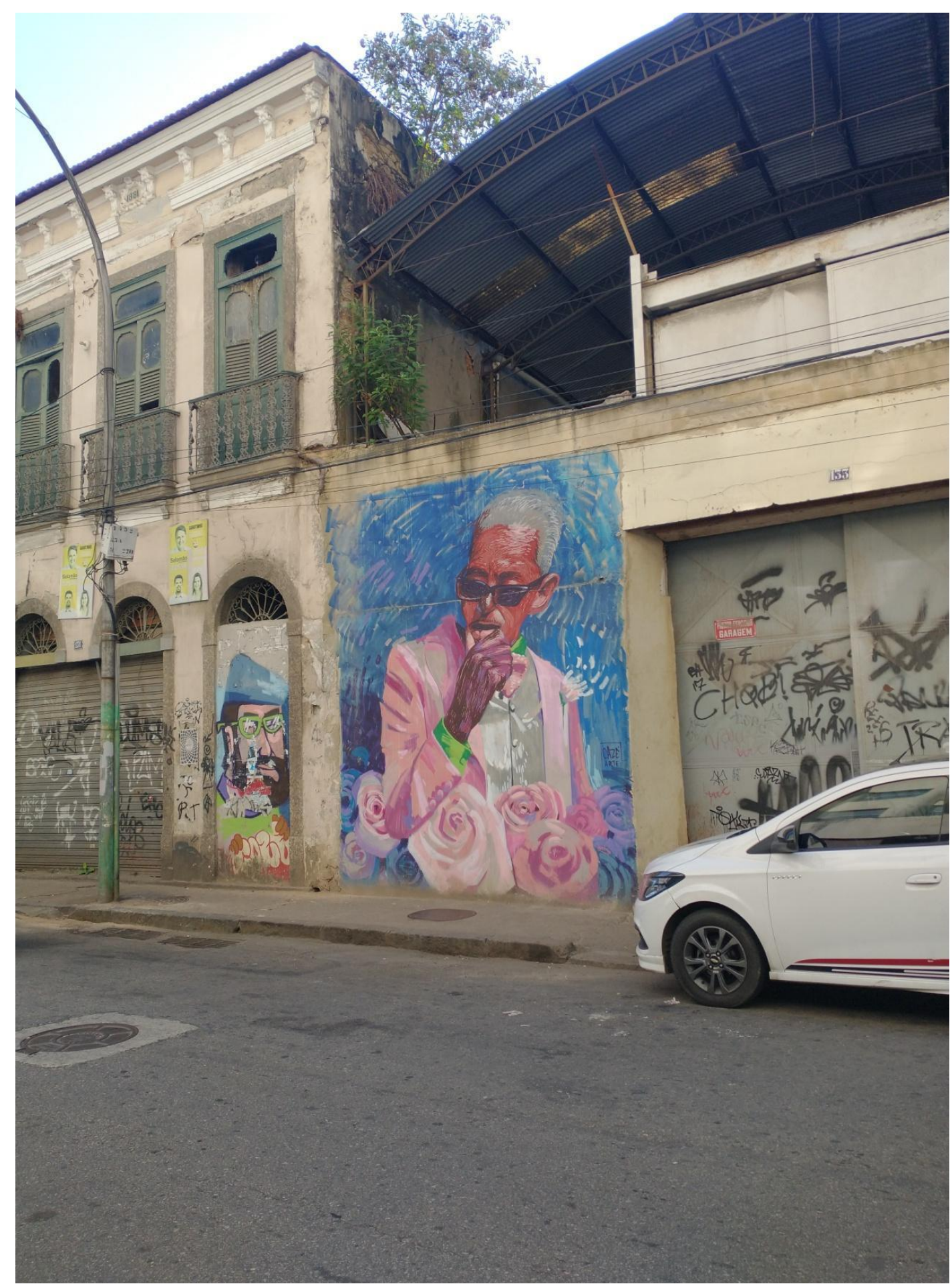

Fonte: Acervo pessoal, 2020.

Figura 7 - Dois bares da Lapa durante a manhã. 
Cidades em metamorfose: memórias, percursos urbanos e imagens

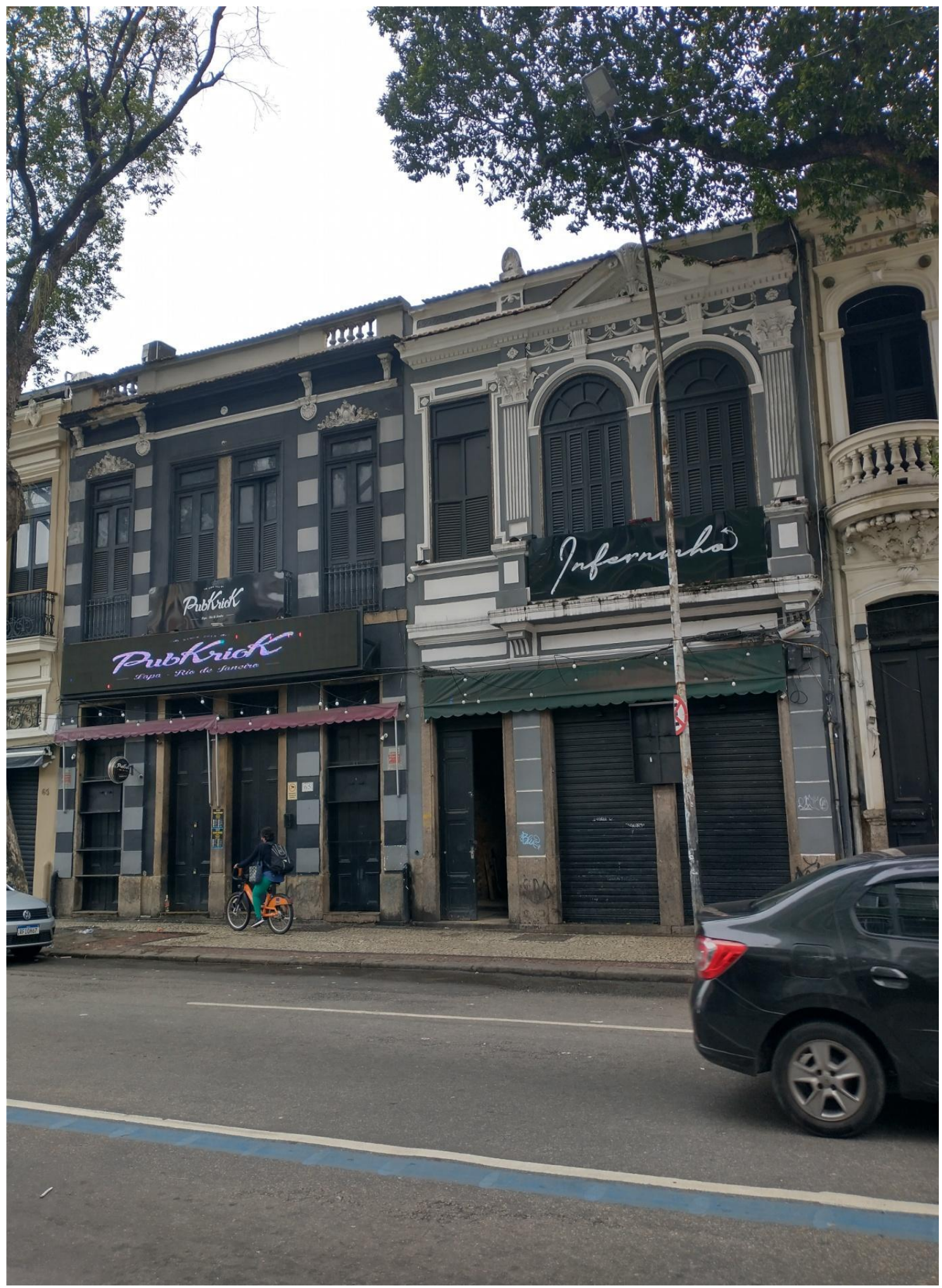

Fonte: Acervo pessoal, 2020.

Figura 8 - Rainha da pipoca, na Rua do Lavradio. 


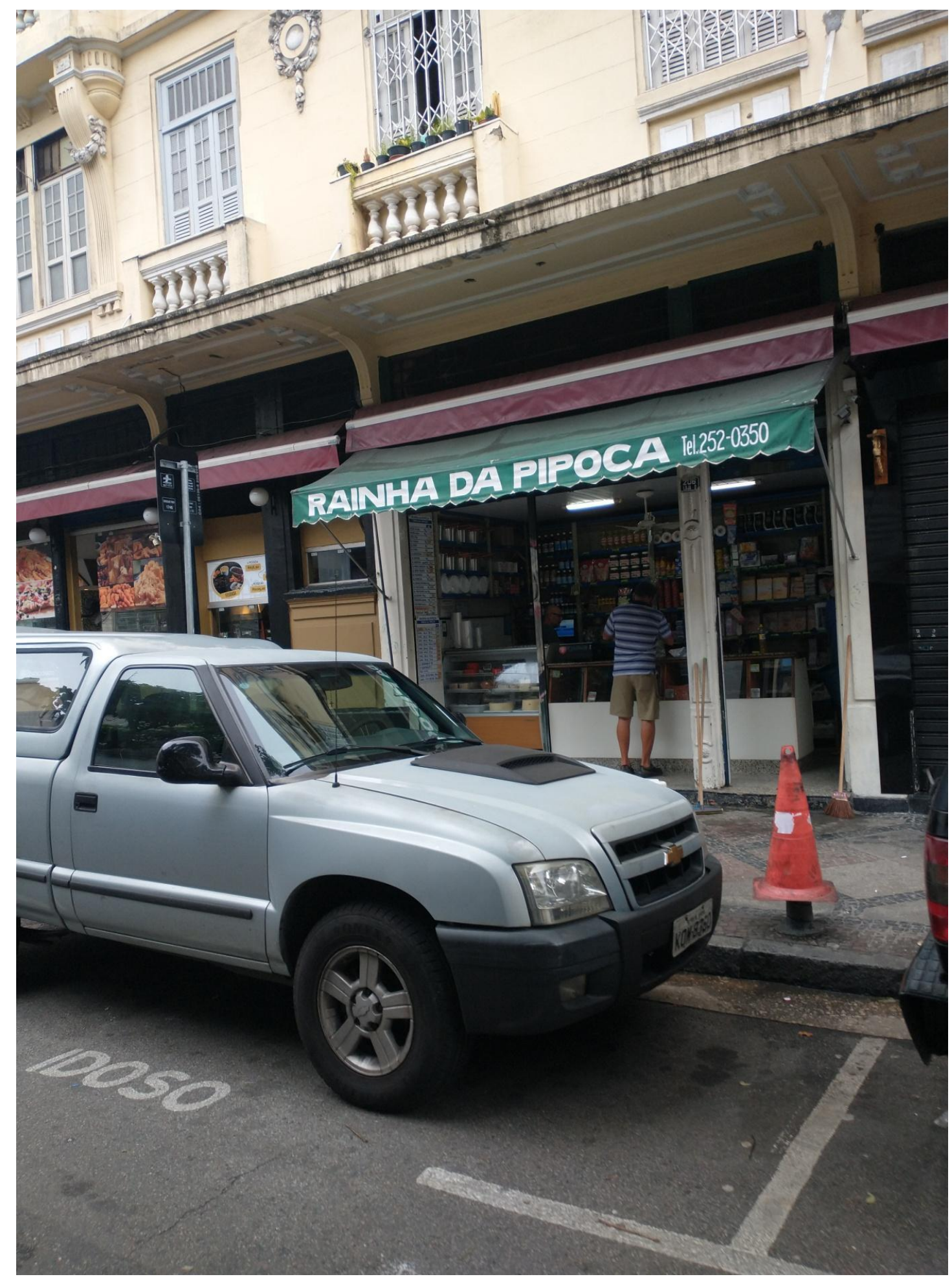

Fonte: Acervo pessoal, 2020.

Comumente encontramos pela Lapa turistas de diferentes nacionalidades e regiões do Brasil reunidos com suas câmeras fotográficas em uma manhã qualquer, vistos, inclusive, aos montes e com facilidade ao longo do ano. Sob os Arcos da Lapa, alguns capturam fotos e ouvem seus guias turísticos que, geralmente mesclando o inglês 
e o espanhol, apresentam uma narrativa sobre a história da Lapa, destacando e exaltando sua vida boêmia, suas ruínas, sua diversidade e seus imponentes Arcos, apresentados, inclusive, como um dos mais importantes símbolos da cidade do Rio.

“Antes" dos Arcos, outro ponto muito frequentado por turistas estrangeiros e de diferentes regiões do Brasil é a Escadaria Selarón ${ }^{4}$, que liga a Lapa ao bairro de Santa Teresa e pode ser acessada pela Rua Teotônio Regadas, seguindo a lateral do Centro Cultural Sala Cecília Meireles, ou por meio da Travessa Mosqueira, um dos trechos mais degradados e estigmatizados do bairro aos olhos da segurança pública, ou ainda pela Rua Joaquim Silva, por onde normalmente os grupos de turistas seguem seu rumo.

Entre esses caminhos até a colorida Escadaria, decorada em azulejos e mosaicos pelo artista chileno radicado no Brasil, Jorge Selarón, cruzamos por cortiços, depósitos de bebidas, pichações, sujeira, pessoas deitadas nas calçadas, além de frequentes casos de furtos, venda e consumo de drogas que comumente ganham destaque em jornais de grande circulação midiática. Por essa caminhada, é possível notar a presença de artistas vendendo artesanatos e pinturas em azulejos expostos em cavaletes nas calçadas, e também lojas de souvenirs, onde são vendidas miniaturas de alguns pontos turísticos do Rio, como os Arcos da Lapa, o Cristo Redentor ou as ondas do calçadão da praia de Copacabana; nesse mesmo percurso encontrarmos ainda pequenos restaurantes e uma grande circulação de ambulantes vendendo bebidas, cangas, óculos de sol e camisas de time de futebol.

Figura 9 - Fragmento da Rua Teotônio Regadas e, ao final, a Escadaria Selarón.

${ }^{4}$ Ver pesquisa etnográfica realizada por Raquel Martini Corriconde (2012) no PPCIS-UERJ, intitulada Nas subidas e descidas da Escadaria Selarón. 


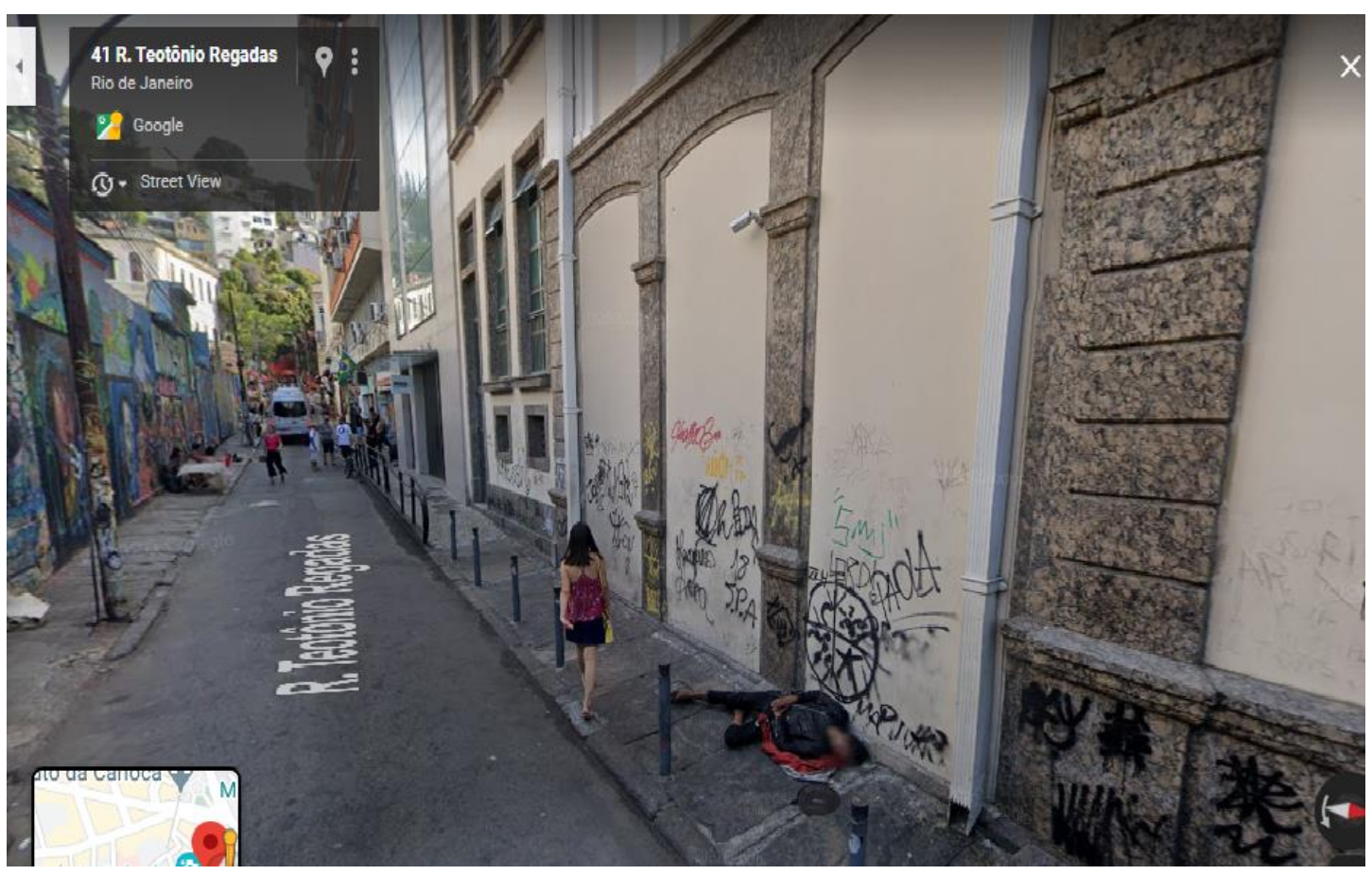

Fonte: Google Street View, 2020.

Figura 10 - Fragmento da Travessa Mosqueira.

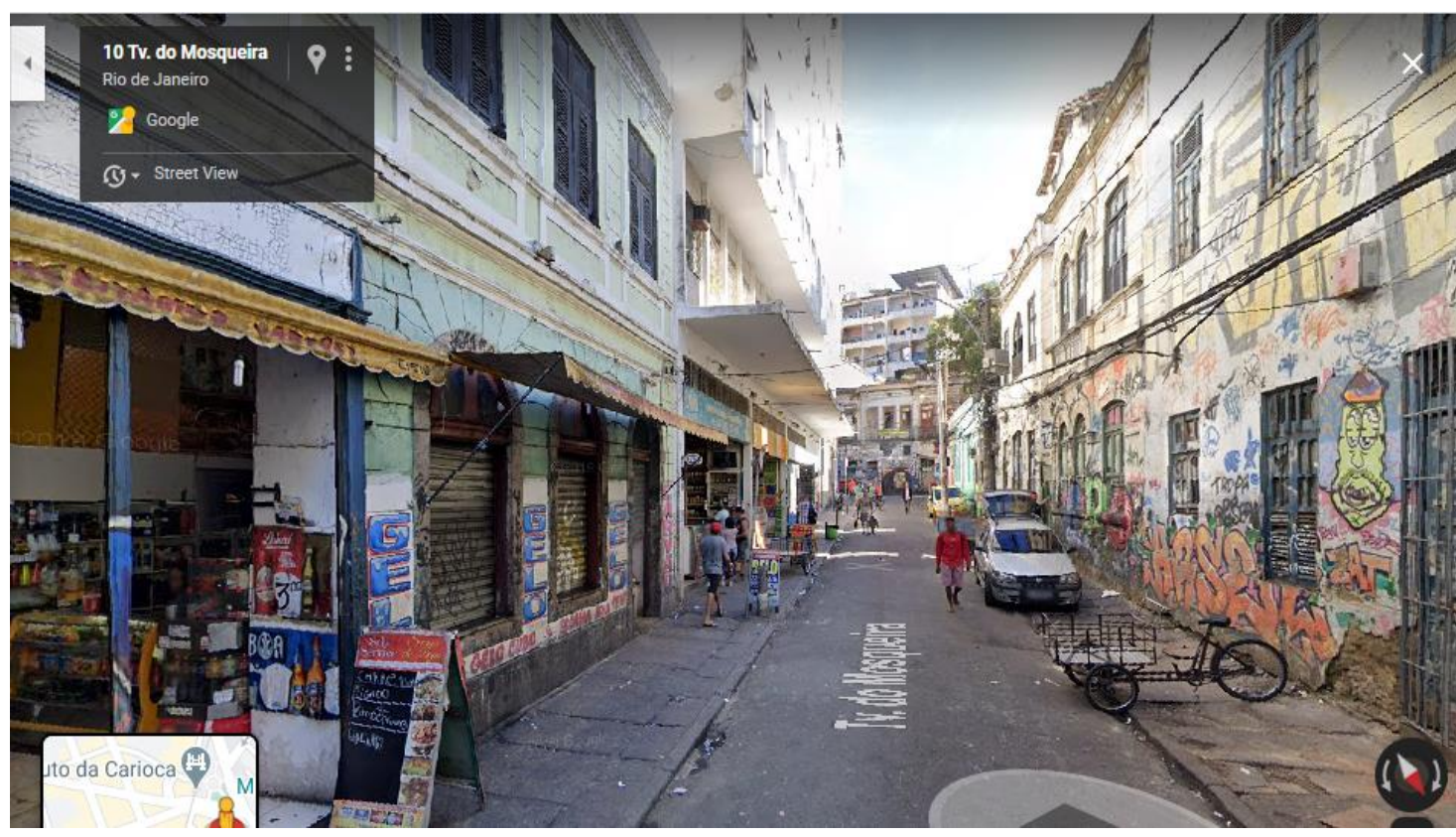

Fonte: Google Street View, 2020.

Figura 11 - Fragmento da Rua Joaquim Silva, a rua da Escadaria Selarón. 


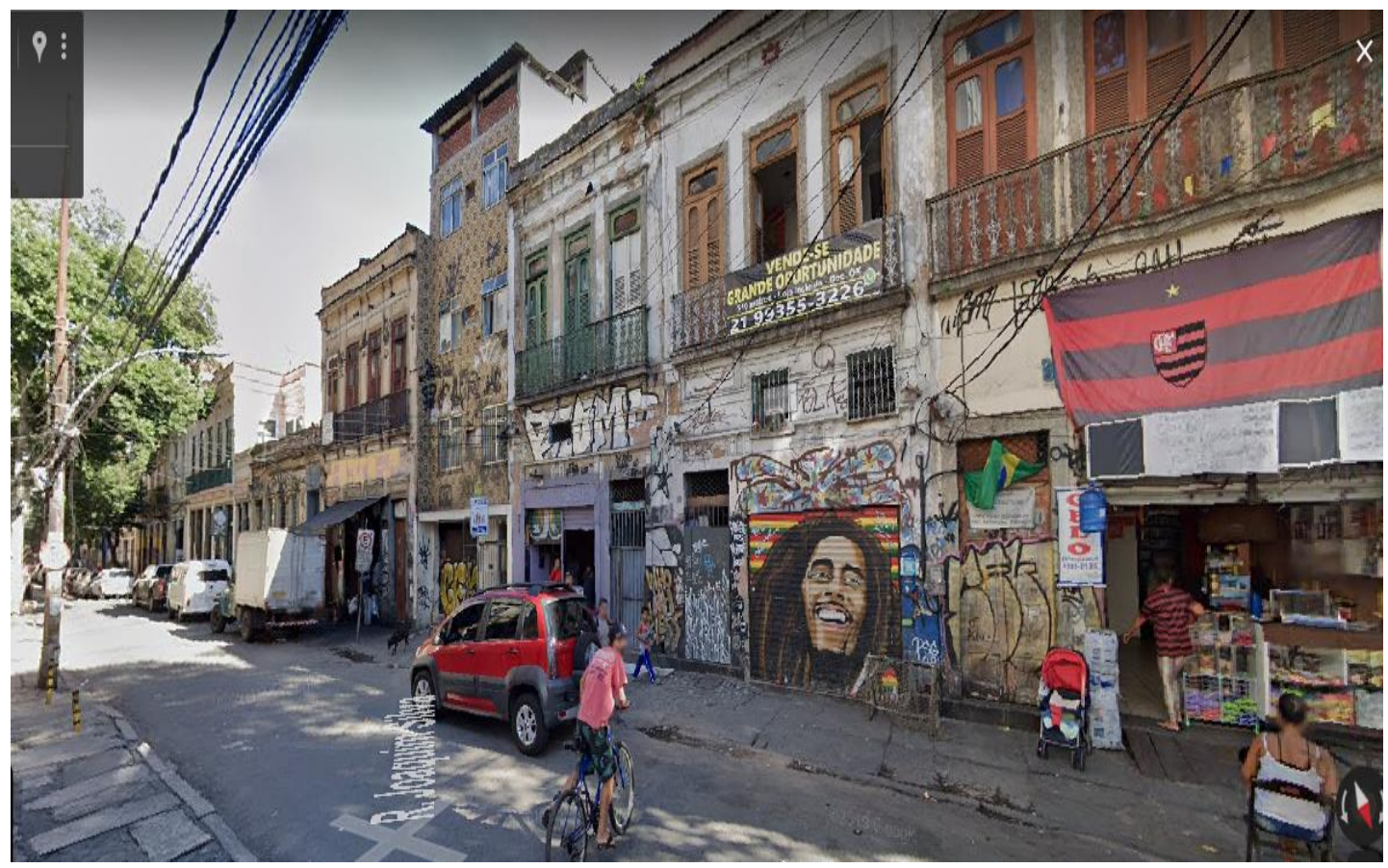

Fonte: Google Street View, 2020.

As imagens apresentadas no curso do texto ilustram fragmentos de um cenário permeado de contradições e sobreposições desenhadas no espaço urbano da Lapa, que concentra comércios, edificações e usos diferentes dos encontrados "do outro lado" dos Arcos tal como relata Fazzioni (2014). Pela Avenida Mem de Sá, logo após cruzarmos os Arcos, podemos visualizar ao anoitecer um aumento significativo do fluxo de usuários nesse espaço da Lapa. Em uma noite de sexta-feira, por exemplo, o ritmo se intensifica pelas calçadas e ruas, onde os bares e restaurantes ficam ainda mais movimentados e podemos encontrar atrativos como rodas de samba, festas e shows de diferentes ritmos, como funk, sertanejo, pagode e pop music norte americana.

Em meio a esses passos que envolvem paradoxos e distinções entre o novo e o velho, holofotes turísticos e ruínas, degradação e valorização, torna-se possível a elaboração de considerações sobre algumas dimensões das dinâmicas urbanas do turismo na região da Lapa, indagando quais histórias e narrativas são elaboradas e contadas no percurso destinado ao turismo dito oficial. Cabendo ainda, dentro dessa reflexão, o questionamento de quais tipos de turismo podem ser observados na Lapa e o que é elencado, resgatado e (des)apropriado como elemento identitário, histórico e cultural pelas dinâmicas do turismo - seja a malandragem, a boemia, a diversidade, os personagens históricos ou mesmo as próprias ruínas. 
Nesse sentido, a partir do que foi aqui brevemente apontado, podemos pensar que caminhar pela cidade e pelo movimento de seu cotidiano significa, ao olhar etnográfico, como pontuado por Hélio Silva (2009), perceber seus ritmos, seus sons, suas temporalidades, texturas, colisões e fissuras que se revelam nos ambivalentes e contraditórios deslocamentos, encontros e movimentos da/na cidade.

Dentro desse quadro metodológico como forma de apreensão das dinâmicas urbanas que delineiam a cidade contemporânea, a etnografia de rua, como salientado por Cornelia Eckert e Ana Luiza Carvalho da Rocha (2013), se faz inicialmente na “exploração dos espaços urbanos a serem investigados através de caminhadas "sem destino fixo" nos seus territórios" (Eckert, Rocha, 2013: 24) por meio da incursão no movimento das ruas e avenidas das cidades a partir do que as autoras descrevem como observação flutuante ou etnografia de duração. Por meio dessa forma de observar e vivenciar a cidade, abre-se caminho para a atenção aos diversos rumos e formas de apropriação e deslocamentos da vida urbana, além dos múltiplos usos e ritmos das ruas, que, por sua vez, ampliam as formas de observação das urbanidades e atalhos que fazem a cidade e dos próprios modos do exercício etnográfico.

Por essa direção, no decurso da etnografia de e na rua, a técnica de investigação do cotidiano urbano e da experiência do espaço vivido da rua "estando lá" e situando o lugar do pesquisador por seus deslocamentos e caminhadas analíticas constantes no espaço e tempo das ruas, faz com que seu propósito não se restrinja somente a observação para a sua cidade por meio de processos de "reinvenção/reencantamento de seus espaços cotidianos, mas capacitá-lo às exigências de rigor nas observações etnográficas ao longo de ações que envolvem deslocamentos constantes no cenário da vida urbana.” (Eckert, Rocha, 2013: 27).

Com isso, aos olhos e experiências do etnógrafo urbano, a cidade torna-se um território fluido, caleidoscópico e fragmentário, por onde por meio da etnografia de e na rua se torna possível que se observe não apenas o "nativo", mas, sobretudo a si mesmo em contato e trocas com o que muitas vezes instituímos como "outro" e, também, com "uma diversidade de micro-eventos de interação a qual ele próprio interage ou reage conforme a situação experienciada". Conforme situam as autoras,

[...] sem dúvida, na etnografia de rua o perfil de uma comunidade, indivíduo e/ou grupo se configura aos poucos pois o etnógrafo trabalha pacientemente a partir de colagens de seus fragmentos de interação. Isto porque uma cultura 
urbana se expressa não só por convenções gestuais, de linguagens recorrentes, especializações profissionais de seus portadores, mas se apresenta igualmente através de suas práticas ordinárias, saberes e tradições com as quais o pesquisador precisa familiarizar-se neste deslocamento em espaços que são, ou não, o seu próprio lugar de origem. Na busca do encontro e diálogos menos fortuitos que aqueles que os deslocamentos na rua permitem ao etnógrafo, a cumplicidade dos pequenos gestos, sorrisos ou olhares dos habitantes da rua, moradores locais, comerciantes, freqüentadores, mendigos, vendedores ambulantes, menino(a)s de rua, feirantes, pode significar um convite a aproximação mais duradoura. Nestes rituais de sedução e jogos de conquista da atenção do Outro, desvenda-se a lógica da criação dos papéis através dos quais constroem-se os personagens do antropólogo e do nativo em interação. [...] Neste sentido a etnografia "na" rua consiste no desenvolvimento da observação sistemática de uma rua e/ou das ruas de um bairro e da descrição etnográfica dos cenários, dos personagens que conformam a rotina da rua e bairro, dos imprevistos, das situações de constrangimento, de tensão e conflito, de entrevistas com habitués e moradores, buscando as significações sobre o viver o dia-a-dia na cidade. (Eckert, Rocha, 2013: 25).

Sendo assim, como sugerido por Eckert e Rocha enquanto forma de observação das tramas da cidade contemporânea, o olhar para o cotidiano dos fluxos urbanos permite que possamos refletir acerca das transformações e mudanças na ambiência e comportamento corporal das cidades, assim como elaborar elucidações acerca de suas desterritorializações e reterritorializações. Essas dinâmicas dizem respeito, em última instância, aos sentidos e significados atribuídos aos pontos de encontro, de orientação e interação de uma multiplicidade de modos de vida, ocupação, circulação e conflitos que (de)formam o cotidiano do espaço urbano das cidades, auferindo-lhes novos contornos pelas táticas e reinvenções mobilizadas a partir da complexa relação dos e das habitantes com o poder público em suas diversas dimensões e emaranhados.

Por esse caminho, cabe ressaltar que ao cruzar sobreposições de camadas de histórias por essa região da cidade, observa-se um espaço urbano construído de forma heterogênea por forças vivas múltiplas, que desenham e reinventam a cidade cotidianamente de formas diversas e ambivalentes. Territorialidades e corporalidades que muitas vezes nascem sorrateiras, pelas encruzilhadas, nas ruínas, becos e arcos, ou ainda à sombra ou à luz dos ofuscantes holofotes turísticos projetados sobre a Lapa carioca.

\section{Considerações Finais}

O que este trabalho buscou revelar por meio de alguns fragmentos sobre a Lapa, bairro central do Rio de Janeiro, aponta para uma concepção de espaço urbano 
apreendido por meio de um cotidiano que tem como marca fundamental suas sobreposições, seus paradoxos e contradições, que puderam ser observadas em pesquisa de campo realizada nessa região da cidade acompanhando algumas dinâmicas do turismo na configuração da Lapa nos dias de hoje.

A abertura de uma olhar para seu cotidiano pela perspectiva das transformações cotidianas e ambivalentes formas de usos, em seus movimentos e interações distintas, torna-se possível dentro dos debates sobre a cidade contemporânea e do reconhecimento que a região estudada encontra-se fortemente envolvida pelas dinâmicas impulsionadas pelo mercado do turismo no Rio de Janeiro, sendo afetadas, sobretudo, devido aos megaeventos (Copa do Mundo e Olimpíadas) e programas de segurança pública que impactaram a cidade em diferentes níveis e instâncias.

Desse modo, considerando o cenário da Lapa investigado por meio da etnografia de rua, muitos ritmos, cruzamentos e distintas formas de uso do espaço urbano puderam ser visualizados, compartilhados e, muitas vezes, experienciados. A Lapa dos turistas, dos comerciantes, ambulantes, entregadores de delivery, sambistas, dos despachos nas esquinas, das igrejas, dos funkeiros, dos bêbados, das pessoas em situação de rua, das ocupações urbanas, dos jogos do Flamengo nos bares, das prostitutas e dos michês, que são, aqui, pensados não como meros personagens e objetos de análise das histórias e culturas das ruas, mas como sujeitos que fundamentalmente a constroem.

\section{Referências}

BARTOLY, Flavio Sampaio. Da Lapa boemia à Lapa reificada como lugar do espetáculo: uma análise dois de periódicos da história da produção do lugar na cidade do Rio de Janeiro. In: Revista Geográfica de América Central-Edição especial EGAN, Costa Rica, 2011.

CARRICONDE, Raquel Martini. Nas subidas e descidas da Escadaria Selarón, Lapa/RJ. Rio de Janeiro: Programa de Pós-Graduação em Ciências Sociais PPCIS/UERJ, 2012. [Dissertação]. Universidade Estadual do Rio de Janeiro, Rio de Janeiro, 2012.

CARUSO, Haydée. Entre ruas, becos e esquinas: a construção da ordem na Lapa carioca. Brasília: Editora Universidade de Brasília, 2016. 
CASCO, Ana C. O Arco das Lapas: um estudo de antropologia urbana. Rio de Janeiro: Programa de Pós-Graduação em Antropologia Social - PPGAS/Museu Nacional/UFRJ, 2007. [Tese]. Universidade Federal do Rio de Janeiro, 2007.

CERTEAU, Michel de. A invenção do cotidiano: artes de fazer. Petrópolis/RJ: Editora Vozes, 2014.

DELGADO, Manuel. Apuntes metodológicos para sociedades sin asiento. In: Sociedades movedizas: pasos hasta una antropología de las calles. Barcelona: Anagrama, 2007. Cap. 4. p. 128-149. El espacio público como ideología. Editora Catarata, Madrid, 2011.

ECKERT, Cornelia; ROCHA, Ana Luiza Carvalho da. Etnografia de e na rua: estudo de antropologia urbana. In: Etnografia de rua: estudos de antropologia urbana. Ana Luiza C. da Rocha e Cornelia Ecker (orgs). Porto Alegre/RS: Editora da UFRGS, 2013.

FAZZIONI, Natália Helou. Entre a rua e o bairro: etnografia de um espaço em movimento. In: Iluminuras, v. 16, n. 36, Porto Alegre, 2014. pp. 287-307.

GUTERMAN, Bruna da Cunha. Cidade-produto, bairro-marca: como a Lapa está se tornando o mais carioca dos bairros. Tese (doutorado) - Universidade Federal do Rio de Janeiro, Instituto de Pesquisa e Planejamento Urbano e Regional, 2012.

HERSCHMANN, Micael. Lapa, cidade da música: desafios para o conhecimento do Rio de Janeiro e da indústria da música independente nacional. Rio de Janeiro/RJ. Editora Mauad X, 2007.

JACQUES, Paola Berenstein. Zonas de tensão: em busca de micro-resistências urbanas. In: BRITO, Fabiana Dutra; JACQUES, Paola Berenstein (org). Corpocidade: debates, ações e articulações. Salvador/BA: EDUFBA, 2010.

MAIOR, J. L. S. "Lei geral da Copa: explicitação do estado de exceção permanente". In: Brasil em jogo: o que fica da Copa e das Olimpíadas?. Rio de Janeiro: Boitempo, 2014.

MARTINS, Gabriela Rebello; OLIVEIRA, Márcio Piñon de. O que está acontecendo com a Lapa? Transformações recentes de um espaço urbano na área central do Rio de Janeiro - Brasil. In: XII Encontro de Geógrafos da América Latina, 2008, Montevideo. XII Encontro de Geógrafos da América Latina, 2008.

SILVA, Hélio R. S. Travesti: a invenção do feminino. Rio de Janeiro: Relume-Damará: ISER, 1993. A situação etnográfica: andar e ver. In: Horizontes Antropológicos, Porto Alegre, ano 15, n. 32, 2009. pp. 171-188.

SOUZA, Andre Felix de. Lapa: da sociabilidade na cidade para a sociabilidade da cidade. In: Espaço Aberto, PPGG - UFRJ, V. 5, N.2, p. 61-78, 2015

VELHO, Gilberto. Observando o familiar. In: VIANNA, Hermano; KUSCHNIR, Karina; CASTRO, Celso (org). Um antropólogo na cidade: ensaios de antropologia urbana. Rio de Janeiro: Zahar, 2013. 
VIANA, Lucio Hanai Valeriano. A ideologia na produção do espaço: os megaeventos como agentes difusores da ideologia neoliberal. In: Cadernos Metrópole, v.21, n. 44, São Paulo, 2019. pp. 79-97.

Data de submissão: 30 de agosto de 2021

Data de publicação: 20 de dezembro de 2021 